Article

\title{
Developing Nordic Cooperation in Renewable Electricity Policy: Exploring Views from Finland and Sweden
}

\author{
Sarah Kilpeläinen \\ Faculty of Management and Business, Tampere University, 33014 Tampere, Finland; E-Mail: sarah.kilpelainen@tuni.fi
}

Submitted: 30 June 2020 | Accepted: 28 August 2020 | Published: 3 November 2020

\begin{abstract}
Calls for extending Nordic cooperation in the energy sector consider increased cooperation to be a tool to further support the creation of a smart Nordic energy system and realize the sustainable energy transition. To enhance our understanding of the state of Nordic energy cooperation, this article focuses on renewable electricity policy development in Finland and Sweden against the backdrop of facilitating and accelerating the Nordic energy transition. Building on previous research, the respective policy landscapes in Finland and Sweden will be scrutinized with insights from expert interviews, allowing the highlighting of the role of the actors in shaping the national and international energy transition policy. Ultimately, the article will explore the possibilities to enhance Nordic cooperation and question a possible future institutionalization of Nordic energy cooperation from the perspectives of Finland and Sweden. The aims of the article are twofold. First, to analyze the current policy mixes in Finland and Sweden with a special focus on bottlenecks and development needs and, second, to explore the viewpoints of the stakeholders from these two countries regarding potential and bottlenecks for developing Nordic energy cooperation.
\end{abstract}

\section{Keywords}

energy policy; energy transition; Finland; Nordic; renewable electricity; renewables; Sweden

Issue

This article is part of the issue "Rediscovering Nordic Cooperation" edited by Anne Elizabeth Stie (University of Agder, Norway) and Jarle Trondal (University of Agder, Norway/ARENA University of Oslo, Norway).

(C) 2020 by the author; licensee Cogitatio (Lisbon, Portugal). This article is licensed under a Creative Commons Attribution 4.0 International License (CC BY).

\section{Introduction}

The Nordic energy transition is based on a set of ambitious policy goals agreed upon in the main strategies pertaining to energy and climate as interconnected policy fields. These national strategies are reflected on the regional level, for example, through the Declaration on Nordic Carbon Neutrality, adopted in 2019. Striving for carbon neutrality and the electrification of interconnected sectors with renewable electricity (NORDEN, 2019; TNCEP, 2020) encompasses a variety of policy challenges. The need to transform the power sector and electrify heat and transport sectors are a part of the drivers for this vision (TNCEP, 2020). This entails the coordination of a variety of national policies in a complex policy environment that requires speedy developments so as to address the multitude of challenges set out in the respective national strategies.
These ambitious goals and already realized achievements in the energy sector position the Nordic region as a frontrunner in the energy transition, having an exemplary function within the EU and globally. Simultaneously, the Nordic progress also raises questions about possible acceleration and how Nordic cooperation can be one tool for accelerating the energy transition.

Ambitious goals, as a part of high-level policy strategies, must be operationalized at the policy level. Here, actors and policy processes are vital. The question of interests and their influence on supporting or hindering a concerted effort must be especially considered in this context. The focus here is on these themes in line with the calls found in the policy mix literature to focus more on actors and policy processes and on how these, in turn, can affect the content of policy mixes (Rogge, Kern, \& Howlett, 2017, p. 2), with efforts to further account for the role of politics in shaping policy (Meadowcroft, 2011). 
Empirically, the focus is on policies aimed at supporting the development of renewable electricity in Finland and Sweden. Finland and Sweden share interconnectors and are planning a further interconnector to be taken into use in 2025 (Fingrid, 2016). Additionally, they share similar characteristics influencing the development of their energy system toward having a higher share of renewable sources. They are sparsely populated Nordic countries with population centers in the South requiring the development of North-South transmission capacities; they share a similar cold climate, have energy-intensive industries and long transport distances. Additionally, both Finland and Sweden have a strong bioenergy component in their energy mixes as well as a share of nuclear energy to support the decarbonization of their energy mixes. As opposed to Finland, where wind power has been slower in gaining traction, Sweden also has a well-developed capacity in terms of wind power generation (IEA, 2019, p. 100).

The aims of this article are, first, to outline and discuss the policy mixes, as they pertain to renewable electricity support in Finland and Sweden, and, second, to discuss the opportunities and challenges for Nordic cooperation in developing renewable energy support policies in the future. To do so, Section 2 introduces the theoretical background for this article, focusing on policies, the need to better understand actors involved, and the ways in which the potential for Nordic energy cooperation has been seen in the literature. Section 3 introduces the data set. Section 4 draws on the interview data to analyze the policy landscape in both Finland and Sweden before focusing on the development of Nordic cooperation. Finally, Section 5 presents the conclusion of the article.

\section{Theoretical Background}

National strategies for climate and energy encompass a set of interlinked goals for the development of the energy sectors and the development of electricity from renewable sources. Putting these goals into practice requires a move from strategies to policy instruments for implementing energy transitions and the need to better understand these processes of policymaking, including a focus on how different actors shape the possibilities for operationalizing high-level strategies into policies. This move from the abstract level to the operational level is of importance for: 1) understanding different approaches for developing and implementing national and regional policy mixes, 2) understanding the ways in which policies develop through inputs from a wide actor base, and 3) understanding the role of actors and a widening actor base.

\subsection{Energy Transition Policies}

How to move from high-level strategies and how policies situated under the umbrella of these wider strategies de- velop have been focus areas in the literature on policy mixes for energy transitions. Policy mixes are understood as consisting of respective interacting policy instruments as well as long-term strategies, characteristics, such as consistency and coherence, and the ways in which policy processes shape the development of policy mixes (Rogge \& Reichardt, 2016). Recent research on policy mixes has focused on paying sufficient attention to the complexity, interactions, and interdependencies of different elements of a policy mix as well as focusing on the temporal dynamics and the situatedness of policies under wider frameworks (Edmondson, Kern, \& Rogge, 2019). The temporal dimension and the iterative nature of policymaking are core components given the long timeframes of transitions, where instruments will change according to the changing objectives and stages of innovation (Turnheim et al., 2015).

Analyzing the development of policies allows for better insight into the political processes underpinning their development and provides an opening for better understanding the variety of actors involved. Additionally, the role of the actors and institutions in shaping and developing the energy transition policy mixes is central in moving beyond privileging structure at the expense of agency and in understanding the ways in which the actors can play different roles at different times (Flanagan, Uyarra, \& Laranja, 2011, p. 706).

\subsection{Focusing on Actors}

Recent research emphasizes the understanding of policy as a socially constructed ideational framework (Kuzemko, Lockwood, Mitchell, \& Hoggett, 2016). In this context, research focuses on how actors are shaped by a "regulative, normative and cultural-cognitive rule system" and on institutional barriers as counterbalances to dominant approaches rooted in energy economics and engineering (Tenggren, Wangl, Nilsson, \& Nykvist, 2016, p. 150). Lindberg, Markard, and Andersen (2019, p. 2), stress the importance of the actors' roles and preferences as these influence the policy process as well. This aligns with calls to focus on actors and politics in the study of policy mixes (Flanagan et al., 2011; Rogge \& Reichardt, 2016).

Here, it is assumed that a focus on the policies and involved actors furthers our understanding of what works in national settings as well as the regional level of cooperation in renewable energy policies. Focusing on the role of these policies in supporting the development of Nordic cooperation on the renewable electricity policy also connects to the narrative of the Nordic countries as leaders in this field (Sovacool, 2017) that are possibly able to accelerate transitions with regard to EU-level activities.

This article focuses on the policies and their development, in the cases of Sweden and Finland, regarding renewable electricity supply and the potential they provide for developing Nordic energy cooperation. The analysis will focus on the defining features of these policies and 
on the perspectives of the involved actors. The analysis will also ask to what extent these policies can serve as points of departures for Nordic cooperation on renewable electricity policy.

\subsection{Nordic Energy Cooperation}

The Nordic dimension in the implementation of respective national climate and energy strategies features strongly in debates on realizing the energy transition in the region. Additionally, the current Nordic Programme for Co-operation on Energy Policy highlights renewable energy and the Nordic electricity market as key areas for cooperation (Nordic Council of Ministers, 2017).

The Nordic Council of Ministers for Business, Energy, and Regional Policy commissioned a report in 2017 with the aim of strategically reviewing Nordic cooperation in the field of energy and its potential for development in the future (Ollila, 2017). Highlighting the strength of the existing cooperation and political will as a key driver, cooperation is understood as a tool to reach national goals more effectively while creating "the smartest energy system in the world" in a cost-efficient way (Ollila, 2017, p. 10). Apart from supporting national goals, the importance of a "systematic, strategic and political approach to cooperation, in order to strengthen the Nordic voice, raise the Region's profile and secure Nordic influence in international forums - in particular the EU" (Ollila, 2017, p. 9), alongside the consensus-based nature of cooperation is stressed in the Nordic Council of Ministers report. One proposal relates to conducting Nordic analyses of the impact national policies can have on neighboring countries. Concerning EU-level cooperation, it is suggested that a strong Nordic voice can aid in increasing influence and in promoting the adaption of Nordic solutions on a global scale (Ollila, 2017, p. 13). Developing cooperation is also grounded in meeting the challenges stemming from transitioning to a higher share of renewables, as a well-integrated grid supports the expansion of fluctuating renewables. The report also mentions debates on support for renewable energy that focus on striking a balance between incentivizing specific energy sources and technology neutral schemes. Here, focusing on evaluating the trends in technological developments is seen as useful in contributing to this debate. Also, the need for a clear vision to involve the Baltic countries in energy cooperation in the region has been mentioned (Ollila, 2017, p. 30).

In a recent report, the Nordic transmission system operators refer to the increased complexity of the system, as a result of becoming more integrated and more automated, necessitating new approaches by regulators, transmission system operators, and market stakeholders to ensure successful future development. Among the main identified challenges are increasing flexibility and the need to ensure adequate transmission and generation capacity. Price signals can be distorted by unsuitable support schemes, and the ensuring of ade- quate capacity can benefit from coordinating subsidies on the regional level. Ensuring transmission adequacy then requires regional coordination and the balancing of European, Nordic, and national perspectives on developing the transmission system to meet future system challenges. Here, the common goals for developing the transmission grids in the Nordics are valuable (Statnett, Fingrid, Energinet.dk, \& Svenska Kraftnät, 2016, pp. 3-6).

Karimi, Lund, Skytte, and Bergaentzlé (2018) focus on the ways in which EU, Nordic and national polices set the framework for the energy system flexibility while also unintentionally creating barriers, for example, by preferring specific solutions. Insufficient market signals as well as uneven frameworks for different renewable energy sources in national frameworks are detrimental to market flexibility. Fiscal policies have a strong role to play here, as subsidies or tax exemptions can give a comparative advantage to specific resources or technologies, resulting in market distortions. Consistent fiscal policies, dynamic taxation for electricity as well as the abolishment of support during periods of negative prices are possible tools for mitigating the negative effects of support policies and leveling the playing field. The national context plays a key role in applying these recommendations, as a core benefit of Nordic cooperation in the ongoing energy transition is the enabling of more efficient solutions without side-lining the respective national needs. Thus, cooperation does not automatically mean a focus on harmonization; instead, coherence of frameworks and policies should be the focus (Karimi et al., 2018, p. 5).

Taken together, the complexity of the policy challenge ahead is acknowledged, and bottlenecks are identified while also building on the positive experiences with regard to cooperation in the field of energy in the Nordics. Implementation requires the translation of highlevel priorities into specific policy measures in the respective countries and the spelling out of the benefits to be gained by cooperation.

\section{Data Set and Method}

The data set for this article consists of twelve semistructured expert interviews conducted in March and April 2020 (see Table 1). These approximately one-hourlong interviews were conducted with stakeholders in Sweden $(n=5)$, Finland $(n=6)$, and in Nordic organizations $(n=1)$, representing the public sector as well as selected interest groups and businesses. Taken together, these interviews form an in-depth picture of these stakeholders' viewpoints. The interviewees represent the key actors dealing with renewable electricity in the region and, thus, can provide inputs for gaining a better understanding of both the respective national situation and the Nordic situation. These interviews also allow us to get a better picture of the current discussions taking place in policy circles. At the same time, the small sample size of the expert interviews limits the possibilities of having a more comparative approach. The interviews followed a 
semi-structured themed approach to allow respondents to elaborate freely on the topic while taking their specific expertise into account. The themes are based on the analytical framework, exploring the adopted support policies, current as well as future bottlenecks in developing the renewable electricity policy, the perception of the process of policymaking, the current situation regarding Nordic cooperation in the field of renewable electricity as well as a view on the future regarding the development of Nordic cooperation. The interviews were conducted online, recorded, and transcribed. The interview transcripts were then coded in ATLAS.ti against the themes of the theoretical framework (see Section 2), which provided an overview of the data and enabled the analysis to provide better insight into how respondents evaluated the importance of themes and how these different aspects are connected according to the stakeholders.

The interview data is supplemented with documents focusing on the national energy policy development in Sweden and Finland as well as documents focusing on Nordic cooperation in the field of energy.

Table 1. List of respondents.

\begin{tabular}{ll}
\hline Respondent number & Sector \\
\hline FI01 & Business \\
FI02 & Interest group/business \\
FI04 & Public \\
FI06 & Public \\
FI07 & Public \\
FI10 & Business/network \\
SWE05 & Interest group/business \\
SWE08 & Public \\
SWE09 & Business/network \\
SWE11 & Business \\
SWE12 & Public \\
NORD03 & Public
\end{tabular}

Notes: FI: Finland, SWE: Sweden, NORD: Nordics.

\section{Analysis and Discussion}

This section outlines the main components of the policy framework for renewable electricity in Finland and Sweden. Building on this and the interviews, the evaluation of the policy mix and possible bottlenecks as well as a look at the future follow. The section then focuses on developing Nordic cooperation as seen in the context of Finland and Sweden.

\subsection{Finland}

\subsubsection{Energy Mix}

The Finnish total primary energy supply is dominated by domestic biofuels, nuclear power, and oil imported mainly from Russia. Taken together, biofuels and oil ac- count for over half of the total primary energy supply, with the supply of biofuels increasing by $30.1 \%$ and oil supply decreasing by $8.6 \%$ since 2007 . Finland imports nearly a quarter of its total electricity supply. The share of renewables in the total primary energy supply has grown, on average, by $2.7 \%$ per year. In 2017 , the share of renewables reached $33.4 \%$, the majority of which came from biofuels. In terms of electricity production, $47 \%$ was covered by biofuels, hydropower, and an increasing share of wind, and nuclear power covered about one-third of the electricity production (IEA, 2018, pp. 20-24). Here, hydropower has been an important part of supplying renewable electricity; however, little potential for further developing hydropower is seen, as most capacities have already been exploited, with most of the remaining potential being protected from utilization (Aslani, Naaranoja, Helo, Antila, \& Hiltunen, 2013, p. 509). Finland also imports electricity from Sweden (IEA, 2018, pp. 20-24).

\subsubsection{Strategies and Support Schemes}

The strategic themes in Finland's Government Programme are achieving carbon-neutrality by 2035, becoming the world's first fossil-free welfare society, strengthening carbon stocks and sinks in the short and long-term, making electricity and heat production nearly emission-free by the end of the 2030s, and taking the security of supply concerns into account (Government of Finland, 2019, pp. 34-41). Attaining these policy targets relies on a variety of policy measures, such as the intended phase-out of coal by 2029 , a step-wise phaseout of using oil for heating by the early 2030s, and halving the use of peat in energy production by 2030 (NECP Finland, 2019, p. 12). The National Energy and Climate Plan sets the target of having a $51 \%$ share of renewable energy in the final energy consumption and a renewable energy share of $30 \%$ in road transport by 2030 . Achieving these goals presupposes a wide-ranging electrification of society, an approach that is in line with the policy measures in energy supply highlighted in the Finnish NECP, especially with regard to the promotion of wind and solar power, promotion of biogas in electricity and heat production, a premium system for renewable electricity, and the phasing-out of coal in energy production (NECP Finland, 2019, p. 18).

Supporting renewable electricity depends on a variety of policies. From 2011 to 2018, Finland used a feedin premium scheme for renewable electricity from wind, biogas, forest chips, and wood fuels. While the feed-in tariff has been phased out, plants under the scheme will receive support for up to 12 years after production has started. In 2018, legislation specified the adoption of a sliding premium-based system, using competitive auctions in 2018 and 2019 for mature renewable technologies. Under this system, aid was granted to seven wind power projects, with a total annual electricity production of 1.36 TWh, that are expected to start produc- 
tion in 2021. No new operating aid schemes are included in the Energy and Climate Strategy (IEA, 2018, p. 28; NECP Finland, 2019, pp. 93-102). Additional measures include aid for using forest chips in combined heat and power generation and the Energy Aid Scheme, an investment subsidy mainly focused on commercializing new technologies and the non-ETS sector, including advanced biofuels. This scheme includes support for large-scale demonstration projects (NECP Finland, 2019, p. 94).

Other measures include reducing the taxation on small-scale electricity production and supporting energy advisory services and communication regarding the demand-side response to consumers (NECP Finland, 2019, p. 95).

\subsubsection{Expert Views}

Respondents saw a decrease in the uncertainty in the policy framework over the past decade which they attributed to the reduced risk of policies overlapping and to a more market-based approach in the region (FI01; FIO3), while also pointing out that the importance of the energy and climate topics on the political agenda has grown across the political spectrum (FI01). Respondents representing the public sector evaluated the impact of the direct support schemes positively, with wind power benefitting the most from the feed-in tariff scheme, but less success for small combined heat and power and biogas. The support scheme for forest chips also failed to meet expectations. Discussing the costs of the feed-in tariff in the case of wind power, one respondent pointed to the impact of lower-than-expected electricity prices on the final costs (FIO7) while evaluating the scheme as an overall success, as it not only reached the set targets but also contributed to creating a situation where no government support for wind power is needed anymore (FI04; FI07).

The move away from direct subsidy schemes puts more focus on other measures and the support for new and emerging technologies. This shift in policy focus brings a new set of challenges that, among other things, increase the need for more coordination due to a wider stakeholder base involved in the process (FI07). Additionally, a close evaluation of the underlying objectives of the support schemes is necessary. In this context, a respondent stressed that the design of new support measures necessitates a clear strategy for ways of targeting future measures, using, for example, technology readiness levels as indicators when making decisions to either support research and development or largescale demonstration projects (FI04). The phasing-out of subsidies was welcomed by respondents with a business background, reflecting their preference for further developing market-based approaches and minimal subsidies that help in avoiding market interference (FI01). Overall, these changes in the policy landscape are in line with the support for market-based solutions among the interviewees (FI01; FI02; FI07).
Respondents saw the extension of the stakeholder base from two perspectives. The increasingly complex policy environment leads to a higher number of actors being involved in policymaking, while the nature of the energy transition also aims at including small-scale producers, emerging companies, and citizens. Especially regarding citizens, clear communication and the provision of information are vital to support this development (FI07). This aligns with the Finnish policy efforts to provide more advisory services to consumers.

Interviewees stressed the need to simplify the permitting processes and to further clarify the policy frameworks on both the Finnish and the EU levels alongside the need to ensure investment security for mature technologies. Regarding the further streamlining of the permitting procedures, one respondent stressed that the permitting process should be "smooth, quick, predictable and such that it takes into account the...country-wide need for renewable energy, renewable electricity. And not concentrate too much on too small, local issues in permitting" (FIO1). The importance of improved permitting processes in moving to a distributed energy system in Finland has been stressed in previous research as well (Ruggiero, Varho, \& Rikkonen, 2015).

The connection between bioenergy and the national interest was mainly focused on the possible competition among companies in the sector, though this was not seen as a source of conflict (FIO7).

\subsection{Sweden}

\subsubsection{Energy Mix}

The Swedish energy mix is characterized by hydropower, nuclear power, and bioenergy, accounting for $73 \%$ of the total primary energy supply. Electricity production relies mainly on hydropower and nuclear power in addition to smaller shares of wind and bioenergy. Wind power has grown rapidly, making Sweden a net exporter of electricity. This trend is expected to continue. The composition of the energy mix is characterized by a shift from oil to biofuels and, more recently, wind power (IEA, 2019, pp. 20-24, 100).

\subsubsection{Strategies and Support Schemes}

The overarching targets of the Swedish energy policy are $100 \%$ renewable electricity generation by 2040 , a $50 \%$ share of the final energy consumption to be covered by renewable sources by 2020 , making energy consumption $50 \%$ more efficient in 2030 as compared to 2005, and becoming the first fossil-free welfare state (NECP Sweden, 2020, p. 7). The electricity certificates system, introduced in 2003 and shared with Norway between 2012 and 2020, is the core measure for supporting the development of renewable energy. The year 2017 saw the extension of the system till 2045 (NECP Sweden, 2020 , p. 59). Additionally, the taxes for the microgenera- 
tion of renewable electricity have been reduced. Starting in 2009, Sweden supported the installation of photovoltaic systems for companies, public organizations and private individuals. However, this scheme will expire at the end of 2020. Furthermore, the tax deductions for the investment costs for installing photovoltaic cells or solar heating systems are available for individuals. The storage of self-generated electricity is supported by providing grants to private individuals to support the installation of storage systems with the aim to increase flexibility; this scheme will end in 2020. Measures for avoiding the double-taxation of electricity as well as for an exemption of network charges for consumers using selfgenerated electricity have also been put in place (NECP Sweden, 2020, pp. 60-61).

\subsubsection{Expert Views}

The electricity certificate scheme is the dominant support scheme. The respondents evaluate the scheme as a stable, cost-efficient way of supporting renewables (SWE12). Additionally, discussions to end the systems early have been made based on price signals, as one respondent put it: "We are sort of at a point where...the system still works but there is no job for it" (SWE12). After extending the initial timeframe, the attractiveness of the system for investors grew (SWE08). The sharing of the system with Norway from 2012 to 2020 was evaluated positively. However, a point of conflict during this period was the allocation of renewable energy production between Sweden and Norway. Additionally, the Swedish decision to revise the goal for 2030 was taken without consulting Norway (SWE08). One respondent referred to a further challenge:

The perceived similarity between Sweden and Norway, I'm not really sure whether that has been an advantage or a problem, because, a lot of times, we just assume that it would be the same, sort of; when we were looking into the matter, it really wasn't. (SWE12)

Difficulties arose, for example, from the different distribution of responsibility and power among the participants, leading to tensions but also resulting in valuable learning (SWE12). The overall positive reception among the respondents stands in contrast to research on the first phase of the scheme initially finding that the certificate scheme minimizes short-term social cost but does not contribute to driving technological change, keeping consumer costs low and being equitable (Bergek \& Jacobsson, 2010, p. 1267).

The phasing-out of the photovoltaic support was seen positively, as the cost for photovoltaic systems has been decreasing and as phasing-out provides a way to eliminate parallel subsidies. Additionally, the need to better evaluate the possible impact of the support for solar power in the Swedish context was highlighted given the small role it is expected to play in the Swedish energy system (SWE12). Furthermore, the support for solar has been criticized for having unclear ambitions regarding the expected goals and timeframe. Here, conflict among the Swedish actors regarding the usefulness and scope of the scheme emerged from the interviews (SWE08; SWE05). Additionally, the measures to support solar were seen to be "blurring the system" and creating discontinuity in the industry (SWE12).

The national interest in bioenergy also emerged, with one interviewee noting that Sweden also imports biomass and that the increased demand for biofuels in order to phase-out fossil fuels might increase competition (SWE08).

\subsection{Views on Nordic Cooperation}

Overall, the interviewees saw Nordic cooperation and its future potential in the development of the electric energy systems and the implementation of the energy transition in a positive light. In addition to discussing the different paths for the future of the Nordic energy cooperation in the field of renewable electricity, the interviewees also highlighted the bottlenecks and the phasing-out of subsidies as common themes. The core of Nordic cooperation was clearly located in the development and functioning of the Nordic electricity market. The importance of the Nordic electricity market and of market-based policies was referred to by several respondents (FI01; FI07; SWE09). The phasing-out of the subsidy schemes in Finland and Sweden is expected to positively impact investment security, as it ensures that investors can rely on the market prices of emissions and electricity (FIO2), reflective of the preference for a market-based approach. This preference has also emerged in previous research on Nordic stakeholders as a cornerstone of developing the electric energy system (Kilpeläinen, Aalto, Toivanen, Lehtonen, \& Holttinen, 2019).This contrasts with research more critical of market optimism, instead arguing that market-based incentives need to be better supported by strong policymaking (Moe, 2015; Mundaca \& Markandya, 2016).

Respondents saw the development of transmission infrastructure and the permitting processes as the main bottlenecks in further developing Nordic cooperation. This is in line with previous research (Kilpeläinen et al., 2019; Tenggren et al., 2016, stakeholder reports (Statnett et al., 2016), and the national bottlenecks identified by the respondents in the interviews.

The case of Finnish-Swedish cooperation on bioenergy was brought up by several respondents. The respective national interests were highlighted, though these were not seen to interfere with the possibility of having a common voice on bioenergy issues such as sustainability criteria on the EU level (FI07; SWE05; SWE08). Instead, the possibility of increasing knowledge at the EU level was mentioned as a main feature of Finnish-Swedish cooperation. While the national interest in companies was 
highlighted, the overall benefits were seen to outweigh the concerns about national industries (FI07). Previous research also pointed to disagreement among the Nordic countries over the issue of bioenergy, with Finland being the Nordic country where support for bioenergy, especially in the transport sector, is more pronounced than in the other Nordic countries (Kilpeläinen et al., 2019). However, in the present study, these points of disagreement did not emerge in the interviews, instead, the focus of the discussion on biofuels was on it being a potential area of common interest and cooperation.

The value of Nordic cooperation in the field of energy as a consistent feature of policy cooperation was stressed, with special attention drawn to how the elements of cooperation have become so ingrained in the region that they are taken "for granted" (SWE11). Simultaneously, further institutionalization was seen cautiously. The interviewees highlighted that the existing networks and cooperation channels have been sufficient in bringing about good results and will be sufficient for meeting future challenges. The combination of highlevel cooperation and informal cooperation in the region was valued for matching different use cases and entry points for cooperation. At the same time, the vision for Nordic cooperation in the field of energy, as introduced in the Nordic Council of Ministers report, was seen as having had a positive impact by providing a common point of entry (NORD03). Simultaneously, value was seen in the better coordination processes of developing energy strategies (FI06) and exploring possibilities for better aligning national plans (FI10) within the existing cooperation framework. The importance of informal channels in developing Nordic cooperation has been stressed in previous research as well. Strang $(2016$, p. 8) emphasizes the role of bottom-up cooperation and numerous links among a variety of actors as features that result in cooperation permeating all levels of political life. Whereas this informal cooperation can be seen as a strength of Nordic cooperation, there are also concerns that the strong role of the informal processes of cooperation are due to the existing Nordic institutions not being strong enough (Olesen \& Strang, 2016, p. 27).

Room for improvement is seen in the process of moving from high-level strategies to national policies. However, this is not necessarily a feature of Nordic cooperation only, and, instead, this resonates with the difficulties involved in policy development and the difficulty in moving from overarching goals to the implementation on the ground (Rogge \& Reichardt, 2016). The interviewees also highlighted the need to acknowledge the national differences and interests among the Nordics (SWE08; FI10).

Considering the impact of Nordic cooperation on the EU, the common Nordic voice is described as impactful and valuable, with the Nordic experience in developing cooperation being useful at the EU level. The respondents expect no need to further institutionalize Nordic cooperation at the EU level, instead preferring the use of existing networks to cooperate on EU matters. Additionally, it was highlighted that Nordic cooperation and the benefits it has brought for the Nordic region should be highlighted at the EU level while also stressing that the differences in pace and setting influence regional solutions (SWE11). Referring to the Nordic Council of Ministers report and its vision for Nordic cooperation, the respondents argued that a focus on the topics is preferable to a focus on the institutional arrangements (SWE11). This skepticism toward institutions of Nordic cooperation and a trajectory of moving to more informal consultations has also been noted in the literature (Olesen \& Strang, 2016, p. 36). The limits were clearly referred to with a special focus on the national differences among Nordic countries, which was also evident when discussing the joint certificate scheme by Norway and Sweden or the limits of the cooperation among Finland and Sweden regarding bioenergy. One respondent summed up as follows:

Sometimes when people talk about Nordic cooperation, they have this almost unrealistic dream that if we do it together, everything will be much better....It's not going to work like that, we are different countries and we are members of the Union and it is in the Union where we negotiate. (SWE11)

The impact of the EU legislation is also seen in changing the nature of policy frameworks in the Nordics. Here, a shift from more general high-level policies in the Nordics to more detailed policies, influenced by the EU, was highlighted (FIO6). The increased role of the EU in influencing ways of Nordic cooperation has also been highlighted by Olesen and Strang (2016, pp. 36-39) while also pointing to a lack of a systematized Nordic cooperation in implementing EU directives, again pointing to the strong presence of ad-hoc solutions on a case-by-case basis. This preference is also visible in the stakeholder perspectives in the present study. The role of Nordic cooperation as an intermediate framework between national solutions and EU cooperation also plays a role here, as it makes reforming the institutional framework necessary but also difficult even if there is increased political will for cooperation (Olesen \& Strang, 2016, p. 43). If the actors, as expressed in the interviews, prefer the existing networks and more informal channels, it will impact the possible ways for strengthening and developing Nordic cooperation.

Regarding Nordic cooperation, the Finnish respondents also highlighted the need to look to the Baltics, especially Estonia, and the role Finland can play in serving as a bridge for this cooperation and for putting more focus on this issue (FI10; FIO6). The value added by engaging in dialogue, not only with Nordic but also Baltic countries, on designing and implementing energy and climate policies with a special focus on cross-border impacts has also been highlighted in the latest IEA review of Finland's energy policies (IEA, 2018, p. 16). 
The interviewees also related these issues to the overarching goals of matching the speed of change that policies seek to address with the speed of change in developing, adjusting, and updating the respective policies. The possible role of the industry actors in this acceleration was highlighted by the business respondents (SWE11). An agreement prevailed on the need to find ways to speed up developments in the energy sector by introducing a greater possibility for flexible development to the policy framework (FI10; SWE11; NORD03). This is in line with research exploring the temporalities in energy transitions (Turnheim et al., 2015) that stresses the complexity and path-dependencies of energy transitions.

\section{Conclusions}

This article set out to analyze the development of the current policies regarding renewable energy in Finland and Sweden and to explore the potential for Nordic energy cooperation.

The respective policy mixes of Finland and Sweden, though employing different instruments at different points of time, share a set of commonalities, such as the identification of similar bottlenecks related to the permitting processes and necessary grid development as well as an understanding that a sufficiently flexible regulatory framework is needed in order to develop policies and measures at a speed that will be able to keep up with the energy transition. Additionally, a strong marketbased approach and the need to develop policies in line with this after the phasing-out of the current direct subsidies represent the viewpoints of the stakeholders. Overall, the stakeholders from varying backgrounds see the policymaking processes as sufficiently open and flexible. The positive impact of the Nordic electricity market on operations has been highlighted as well.

The policy field of bioenergy provides a good example of cooperation for Finland and Sweden, where possibly competing national interests do not impede the cooperation for achieving common goals and developing a stronger international position, which was the case with the definition of the sustainability criteria on the EU level.

When it comes to Nordic cooperation on renewable energy, a broad agreement can be found regarding its positive impact and its use as a tool for voicing a Nordic position at the EU and international levels. Here, the trickle-down effect of the broader visions for the future of Nordic cooperation to different levels of policymaking has been observed. At the same time, the respondents were cautious to call for the further institutionalization of Nordic cooperation, arguing that the current mix of high-level cooperation and informal channels of cooperation among a variety of actors are better suited to the ever-changing and complex energy policy environment.

\section{Acknowledgments}

This work has been supported by the Strategic Research Council at the Academy of Finland, project Transition to a resource efficient and climate neutral electricity system (EL-TRAN) grant number 314319.

\section{Conflict of Interests}

The author declares no conflict of interests.

\section{References}

Aslani, A., Naaranoja, M., Helo, P., Antila, E., \& Hiltunen, E. (2013). Energy diversification in Finland: Achievements and potential of renewable energy development. International Journal of Sustainable Energy, 32(5), 504-514.

Bergek, A., \& Jacobsson, S. (2010). Are tradable green certificates a cost-efficient policy driving technical change or a rent-generating machine? Lessons from Sweden 2003-2008. Energy Policy, 38, 1255-1271.

Edmondson, D., Kern, F., \& Rogge, K. (2019). The co-evolution of policy mixes and socio-technical systems: Towards a conceptual framework of policy mix feedback in sustainability transitions. Research Policy, 48(10). https://doi.org/10.1016/j.respol.2018. 03.010

Fingrid. (2016, December 16). Finnish and Swedish transmission system operators making progress with the construction of a new transmission connection: The aim is to take the new connection into use by 2025 [Press release]. Retrieved from https://www. fingrid.fi/en/pages/news/news/2016/finnish-andswedish-transmission-system-operators-makingprogress-with-the-construction-of-a-newtransmission-connection-the-aim-is-to-take-thenew-connection-into-use-by-2025

Flanagan, K., Uyarra, E., \& Laranja, M. (2011). Reconceptualising the 'policy mix' for innovation. Research Policy, 40, 702-713.

Government of Finland. (2019). Inclusive and competent Finland: A socially, economically and ecologically sustainable society. Publications of the Finnish Government. Retrieved from http://julkaisut. valtioneuvosto.fi/handle/10024/161935

IEA. (2018). Finland 2018 review. IEA. Retrieved from https://www.iea.org/reports/energy-policies-ofiea-countries-finland-2018-review

IEA. (2019). Sweden 2019 review. IEA. Retrieved from https://www.iea.org/reports/energy-policies-ofiea-countries-sweden-2019-review

Karimi, P., Lund, D., Skytte, K., \& Bergaentzlé, C. (2018). Better policies accelerate clean energy transition (Policy Brief). Oslo: Nordic Energy Research. Retrieved from https://www.nordicenergy.org/article/ better-policies-accelerate-clean-energy-transition 
Kilpeläinen, S., Aalto, P., Toivanen, P., Lehtonen, P., \& Holttinen, H. (2019). How to achieve a more resourceefficient and climate neutral energy system by 2030? Views of Nordic stakeholders. Review of Policy Research, 36(4), 448-472.

Kuzemko, C., Lockwood, M., Mitchell, C., \& Hoggett, R. (2016). Governing for sustainable energy system change: Politics, contexts and contingency. Energy Research \& Social Science, 12, 96-105.

Lindberg, M. B., Markard, J., \& Andersen, A. D. (2019). Policies, actors and sustainability transition pathways: A study of the EU's energy policy mix. Research Policy, 48(10). https://doi.org/10.1016/ j.respol.2018.09.003

Meadowcroft, J. (2011). Engaging with the politics of sustainability transitions. Environmental Innovation and Societal Transitions, 1, 70-75.

Moe, E. (2015). Renewable energy transformation of fossil fuel backlash: Vested interests in the political economy. New York, NY: Palgrave Macmillan.

Mundaca, L., \& Markandya, A. (2016). Assessing regional progress towards a "green energy economy." Applied Energy, 179, 1372-1394.

NECP Finland. (2019). Finland's integrated energy and climate plan. European Commission. Retrieved from https://ec.europa.eu/energy/topics/energystrategy/national-energy-climate-plans_en\#finalnecps

NECP Sweden. (2020). Sweden's integrated national energy and climate plan. European Commission. Retrieved from https://ec.europa.eu/energy/topics/ energy-strategy/national-energy-climate-plans_en \#final-necps

NORDEN. (2019). Declaration on carbon neutrality. NOR$D E N$. Retrieved from https://www.norden.org/en/ news/stepping-nordic-climate-co-operation

Nordic Council of Ministers. (2017). Nordic programme for co-operation on energy policy 2018-2020. NORDEN. Retrieved from https://www. norden.org/en/publication/nordic-programme-cooperation-energy-policy-2018-2020

Olesen, T. B., \& Strang, J. (2016). European challenge to Nordic institutional cooperation: Past, present and future. In J. Strang (Ed.), Nordic cooperation: A Eu- ropean region in transition (pp. 27-48). London and New York, NY: Routledge.

Ollila, J. (2017). Nordic energy co-operation: Strong today, stronger tomorrow. Copenhagen: Nordic Council of Ministers.

Rogge, K., Kern, F., \& Howlett, M. (2017). Conceptual and empirical advances in analyzing policy mixes for energy transitions. Energy Research and Social Science, 33, 1-10.

Rogge, K., \& Reichardt, K. (2016). Policy mixes for sustainability transitions: An extended concept and framework of analysis. Research Policy, 45, 1620-1635.

Ruggiero, S., Varho, V., \& Rikkonen, P. (2015). Transition to distributed energy generation in Finland: Prospects and barriers. Energy Policy, 86, 433-443.

Sovacool, B. (2017). Contestation, contingency and justice in the Nordic low-carbon energy transition. Energy Policy, 102, 569-582.

Statnett, Fingrid, Energinet.dk, \& Svenska Kraftnät. (2016). Challenges and opportunities for the Nordic power system. Oslo, Helsinki, Fredericia and Sundbyberg: Statnett, Fingrid, Energinet.dk and Svenska Kraftnät. Retrieved from http://www.statnett.no/ Global/Dokumenter/Challenges\%20and\%20 opportunities_Report.pdf

Strang, J. (2016). Introduction: The Nordic model of transnational cooperation? In J. Strang (Ed.), Nordic cooperation: A European region in transition (pp. 1-26). London and New York, NY: Routledge.

Tenggren, S., Wangl, J., Nilsson, M., \& Nykvist, B. (2016). Transmission transitions: Barriers, drivers, and institutional governance implications of Nordic transmission grid development. Energy Research \& Social Science, 19, 148-157.

TNCEP. (2020). Tracking Nordic clean energy progress 2020. Nordic Energy Research. Retrieved from https://www.nordicenergy.org/project/tncep

Turnheim, B., Berkhout, F., Geels, F. W., Hof, A., McMeekin, A., Nykvist, B., \& van Vuuren, D. P. (2015). Evaluating sustainability transition pathways: Bridging analytical approaches to address governance challenges. Global Environmental Change, 35, 239-253.

\section{About the Author}

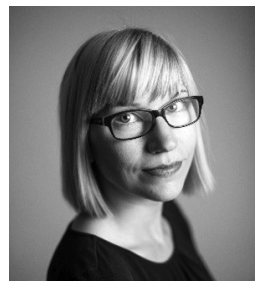

Sarah Kilpeläinen is a Doctoral Researcher in the Faculty of Management and Business at Tampere University, Finland. Her research interests focus on international relations, energy policy and sustainable energy transitions. 